\title{
Innate stimulation of B1a cells enhances the autoreactive IgM repertoire in the NOD mouse: implications for type 1 diabetes
}

\author{
J. Côrte-Real • N. Duarte • L. Tavares • \\ C. Penha-Gonçalves
}

Received: 11 August 2011 / Accepted: 17 January 2012 / Published online: 1 March 2012

(C) Springer-Verlag 2012

\begin{abstract}
Aims/hypothesis We sought to determine whether the presence of natural autoreactive antibodies of B1a cell origin would play a role in the initiation of type 1 diabetes.

Methods We compared IgM repertoires and B1a cell compartments in NOD and C57BL/6 mice. Serum IgM autoreactivity profiles were determined by ELISA and the secretory properties and activation status of B1a cells were characterised by enzyme-linked immunosorbent spot (ELISPOT) assay and flow cytometry. B1a cell response to innate activation was analysed by gene expression assays, ELISA and $\left[{ }^{3} \mathrm{H}\right]$ thymidine incorporation. The effect of NOD IgM produced by B1a cells on NOD.severe combined immunodeficient (SCID) beta cells was examined in cocultures: IgM binding was measured by flow cytometry and real-time PCR was used to study oxidative stress responses.
\end{abstract}

J. Côrte-Real and N. Duarte contributed equally to this study.

Electronic supplementary material The online version of this article (doi:10.1007/s00125-012-2498-0) contains peer-reviewed but unedited supplementary material, which is available to authorised users.

J. Côrte-Real $\cdot$ N. Duarte $\cdot$ C. Penha-Gonçalves $(\triangle)$

Instituto Gulbenkian de Ciência,

Apartado 14,

P-2781-901 Oeiras, Portugal

e-mail: cpenha@igc.gulbenkian.pt

J. Côrte-Real $\cdot$ L. Tavares

CIISA, Faculdade de Medicina Veterinária,

Universidade Técnica de Lisboa,

Lisboa, Portugal

C. Penha-Gonçalves

Education and Research Center,

Associação Protectora dos Diabéticos de Portugal,

Lisboa, Portugal
Results NOD mice displayed increased levels of serum antiinsulin IgM that were independent of the $\mathrm{H} 2$ locus, that were maintained up to prediabetic stages and that correlated with the NOD B1a cell secretion profile. NOD B1a cells had a naturally increased pattern of activation, expressed higher levels of toll-like-receptors (Tlrs) and responded to TLR stimulation in vitro with higher proliferation and increased capacity to secrete anti-type-1-diabetes-related $\operatorname{IgM}$, but produced lower amounts of IL10. IgM of NOD B1a cell origin was able to bind to pancreatic beta cells in vitro and induce expression of inducible nitric oxide synthase (Nos2).

Conclusions/interpretation NOD B1a cells had a lower innate activation threshold for secretion of autoreactive IgM capable of triggering oxidative stress responses on binding to pancreatic beta cells; this provides an early mechanism that contributes to diabetes in a mouse model of type 1 diabetes.

Keywords Autoreactive IgM - B1a cells · NOD · Oxidative stress $\cdot$ Pancreatic beta cell $\cdot$ Toll-like receptor Type 1 diabetes

$\begin{array}{ll}\text { Abbreviations } \\ \text { AAbs } & \text { Autoantibodies } \\ \text { AAgs } & \text { Autoantigens } \\ \text { ds } & \text { Double-stranded } \\ \text { GAD } & \text { Glutamate decarboxylase } \\ \text { IA-2 } & \text { Islet cell antigen 512 } \\ \text { LPS } & \text { Lipopolysaccharide } \\ \text { NAbs } & \text { Natural antibodies } \\ \text { PE } & \text { Phycoerythrin } \\ \text { PerCP } & \text { Peridinin-chlorophyll protein } \\ \text { SCID } & \text { Severe combined immunodeficient } \\ \text { SLE } & \text { Systemic lupus erythematosus } \\ \text { ss } & \text { Single-stranded } \\ \text { TLR } & \text { Toll-like receptor }\end{array}$




\section{Introduction}

The urgency to identify the subtle factors contributing to type 1 diabetes onset and progression is compelled by recent European estimates indicating that the number of new cases of type 1 diabetes in children under the age of 5 years is increasing by more than $5 \%$ each year and predicting the doubling of its incidence in this age group by 2020 [1]. Patients with type 1 diabetes and NOD mice, which are a model of type 1 diabetes, share the spontaneous pathogenic events of type 1 diabetes development [2] in which autoreactive cytotoxic $\mathrm{T}$ cells selectively destroy insulinsecreting beta cells within the pancreatic islets of Langerhans [3]. Nevertheless, studies on NOD mice devoid of B cells have shown that this lymphocyte population is necessary in the diabetic autoimmune process [4] and it is widely accepted that islet-related autoantibodies (AAbs) represent the earliest manifestations of diabetogenesis in both prediabetic patients and in NOD mice [5]. These autoreactive immunoglobulins, of the $\mathrm{IgG}$ isotype, recognise beta cell antigens and are believed to be bystander products of the disease resulting from an ongoing autoimmune process [5]. Thus, at the stage of cytotoxic beta cell destruction, B cells would be highly exposed to beta cell-related autoantigens (AAgs), leading to preferential activation of $\mathrm{B}$ cells with autoreactive potential. In fact, NOD B cell receptor specificity and the capacity of $\mathrm{B}$ cells to present antigens to $\mathrm{T}$ cells are determinant factors in type 1 diabetes progression $[6,7]$. It is believed that long-sustained autoreactive T-B cell interactions condition the repertoire of AAbs typical of prediabetic patients, in whom the beta cell destruction is already in progress, though clinical signs are not yet present. Importantly, B cell-null NOD mice that express a transgene encoding a mutant heavy chain immunoglobulin on the cell surface but that cannot secrete antibodies only partially restored type 1 diabetes, suggesting that circulating antibodies could play a role in the disease [8].

Here, we revisited the role of AAbs in type 1 diabetes pathogenesis with the contention that the early presence of AAbs against beta cell antigens can have implications for type 1 diabetes pathogenesis. Insulitis consists of the infiltration of pancreatic islets of Langerhans by mononuclear cells and is the hallmark of type 1 diabetes initiation. In NOD mice the first insulitic events start at about 3-5 weeks of age but clinical signs of diabetes, due to massive beta cell loss, arise only from 12 weeks onwards [9]. It has previously been shown that NOD mice, but not C57BL/6 nondiabetic control mice, have antibodies bound to beta cells before the development of insulitis. Interestingly, these antibodies are mainly of the $\operatorname{IgM}$ isotype [10] and thus are unlikely to originate in germinal centre reactions. Consistently, young NOD mice have a pronounced repertoire of IgM AAbs [11]. Most of the antibodies of the IgM isotype are spontaneously secreted by B1a cells in the absence of exogenous stimuli or T cell help [12]. The B1a cells are part of the B1 cell subset of lymphocytes that are mainly found in the peritoneal and pleural cavities and at lower levels in the spleen. These B1 cells express low levels of B220 and are subdivided into $\mathrm{B} 1 \mathrm{a}$ and $\mathrm{B} 1 \mathrm{~b}$ subsets based on the presence or absence of the CD5 molecule on their surface, respectively. B1a cells are mostly of fetal origin, do not undergo class switching and affinity maturation and spontaneously secrete natural AAbs [13]. On the other hand, B1b cells are generated mainly during neonatal life in the bone marrow [14] and are involved in the earliest specific reactions against pathogens $[15,16]$. CD5 expression on B1a cells is known to downmodulate responses to B cell-receptor-mediated signalling while favouring IL10 secretion [17, 18]. Interestingly, the $\mathrm{B} 1$ cell activation status is influenced by gut microflora modifications $[19,20]$ and innate stimulation through toll-like receptors (TLRs) can induce their proliferative and antibodysecretion capacities [21]. Thus, B1 can be considered as bridging cells between innate and adaptive immunity.

Importantly, B1a cells have recently been proven necessary for insulitis onset in a transgenic model in which disease is mediated by $\mathrm{T}$ cells recognising pancreatic beta cell antigens [22]. Also, in the $125 \mathrm{Tg}$ mouse, B1a cells prevailed as anti-insulin IgM secretors while B2 cells with the same specificity were anergised [23]. Further, B1a cells are increased in the peripheral blood of type 1 diabetes patients [24] and have been suggested to play a role in the NOD mouse autoimmune process [25].

We have previously hypothesised that natural antibodies (NAbs) of NOD B1a cell origin could promote the initiation of insulitis [26]. However, the link between B1a cell properties, autoreactive IgM profile and autoimmune process triggering has not been established for type 1 diabetes. Here, we dissect this intricate chain of events by analysing the autoreactive repertoire of NOD IgM, by uncovering the B cell subpopulations contributing to its secretion and by examining the impact of these immunoglobulins on NOD beta cell physiology.

\section{Methods}

Mice C57BL/6, NOD, NOD.severe combined immunodeficient (SCID), C57BL/6.H2g7 and NOD.H2b mice, 1-12 weeks of age, were bred and maintained in specificpathogen-free facilities at the Instituto Gulbenkian de Ciência. Insulitis was rare at 3 weeks in NOD female mice (electronic supplementary material [ESM] Fig. 1). Protocols were approved by the competent Portuguese authority, in accordance with international regulations [27].

ELISA and ELISPOT assays ELISAs were used to quantify total IgM and anti-insulin IgM concentrations in mouse sera. 
Total IgM, IgM with reactivity to a pool of type-1-diabetesrelated AAgs, namely insulin, islet cell antigen 512 (IA-2), glutamate decarboxylase (GAD)65 and GAD67 and IL10 levels were measured in cell culture supernatant fractions after TLR stimulation (see ESM Methods).

The number of $\mathrm{B}$ cells secreting IgM with reactivity to type 1 diabetes AAgs, thyroiditis-associated AAgs (thyroglobulin and thyroperoxidase), muscarinic-3-receptor (sialitis-related AAg), systemic lupus erythematosus (SLE)associated AAg (double-stranded [ds]DNA, singlestranded [ss]DNA and histone) or AAg recognised by B1a cells (phosphatidylcholine, phosphorylcholine and dextran) [28] were determined as described elsewhere [29] (see ESM Methods).

Cell analysis and purification Cell suspensions prepared from the spleen and peritoneal cavity were incubated with anti-mouse-Fc-block/CD16/32 (clone 2.4 G2, Becton Dickinson, Franklin Lakes, NJ, USA). Peritoneal B1a cells were identified as $\mathrm{B} 220^{+} \mathrm{CD}^{+}$and $\mathrm{B} 1 \mathrm{~b}+\mathrm{B} 2$ cells as $\mathrm{B} 220^{+} \mathrm{CD} 5^{-}$. Splenic B1a cells were identified as CD23 ${ }^{-} \mathrm{IgM}^{\text {high- }}$ $\mathrm{B} 220^{\text {low }} \mathrm{CD}^{+}$, follicular B lymphocytes as $\mathrm{CD}^{2} 3^{+} \mathrm{IgM}^{\text {low }}$ and marginal zone $\mathrm{B}$ cells as $\mathrm{CD} 23^{-} \mathrm{IgM}^{\text {high }} \mathrm{CD} 21^{+} \mathrm{CD} 5^{-}$. Fluorescein isothiocyanate (FITC)-anti-CD19 (clone 1D3), FITC-anti-IgM (clone R33.24.12), phycoerythrin (PE)-antiCD23 (clone B3B4), peridinin-chlorophyll protein (PerCP) or PE-anti-CD5 (clone 53-7.3), allophycocyanin (APC)-anti-CD45R/B220 (clone RA3-6B2), biotinylated or FITCanti-CD11b/macrophage-1 antigen (MAC-1) (clone M1/ 70), FITC-anti-CD21 (clone 7 G6), PE-anti-CD43 (clone S7), biotinylated-anti-CD86 (clone GL1), FITC-antiCD62L (clone Mel14), biotinylated or PE-anti-syndecan-1 (clone 281-2) and FITC or PerCP-streptavidin antibodies were used for staining. Traceable beads (Beckman Coulter, Brea, CA, USA) were added for counting cells. Flow cytometry (FACSCalibur) was used and analysis performed with FlowJo software (TreeStar, Ashland, OR, USA). Peritoneal and splenic B cells were purified by cell sorting using MoFlo (Dako-Cytomation, Berkeley, CA, USA) or BD FACSAria III cell sorter (Becton Dickinson) with purity above $90 \%$.

RNA isolation and real-time PCR Total RNA from sorted peritoneal B1a cells or from cultured beta cells was obtained using a High Pure RNA Isolation Kit (Roche, Basel, Switzerland) following the manufacturer's protocol. RNA was converted to cDNA with Transcriptor High Fidelity cDNA Synthesis Kit (Roche). The following TaqMan gene expression assays with FAM reporter (Applied Biosystems, Foster City, CA, USA) were used: Tlr2 (Mm00442346 m1), Tlr4 (Mm00445274 m1), Tlr6 (Mm02529782 s1), Tlr7 (Mm00446590 m1), Tlr9 (Mm00446193 m1), Fas (Mm00433237_m1), Nos2 (Mm01309901_m1), Casp3
(Mm01195084 m1) and Ccl2 (Mm00441242 m1). Gene expression was quantified in ABI Prism 7900HT (Applied Biosystems). Relative quantification was obtained after normalisation for mouse GAPDH (VIC/MGB probe) expression using the $2 \Delta \Delta C_{\mathrm{t}}$ analysis method [30].

Lipopolysaccharide stimulation Purified peritoneal B1a cells were cultured in RPMI 1640 complete medium (Gibco, Grand Island, NY, USA) with or without $1-5 \mu \mathrm{g} / \mathrm{ml}$ purified lipolysaccharide (LPS) (Invivogen, San Diego, CA, USA) and supernatant fractions taken for antibody and IL10 quantification by ELISA at day 3 of culture. For proliferation analysis, cells were pulsed in the last $6 \mathrm{~h}$ of culture, harvested and $\left[{ }^{3} \mathrm{H}\right]$ thymidine (Perkin Elmer, Waltham, MA, USA) incorporation measured. Expression of activation markers after 1 day of stimulation was assessed on pooled duplicates using biotinylated anti-CD69 (clone H1.2 F3), biotinylated anti-CD86 (clone GL1), Alexa488-anti-CD25 (clone PC 61) and PerCP-streptavidin.

In vitro transwell cultures Islets of Langerhans were isolated from the pancreas of 9-week-old NOD.SCID female mice by collagenase type $\mathrm{V}$ digestion $(1.4 \mathrm{mg} / \mathrm{ml}$; SigmaAldrich, St Louis, MO, USA) followed by hand picking under a stereomicroscope. Islets were dissociated into single cell suspensions by mechanical and dispase enzymatic treatment ( $5 \mathrm{mg} / \mathrm{ml}$; Roche). Freshly dissociated cells were cultured at $1 \times 10^{5}$ cells per well in Ham's F-10-glutamax medium (Gibco) with $10 \mathrm{mmol} / \mathrm{l}$ glucose (Sigma-Aldrich), $0.5 \%$ BSA, $50 \mu \mathrm{mol} / 1$ isobutylmethylxanthine (SigmaAldrich), $50 \mathrm{U} / \mathrm{ml}$ penicillin and $50 \mu \mathrm{g} / \mathrm{ml}$ streptomycin (Gibco). At $24 \mathrm{~h}$ after this treatment, sorted peritoneal B1a cells $\left(5 \times 10^{5}\right)$ or follicular splenic B cells $\left(5 \times 10^{5}\right)$ were added in transwells $(0.4 \mu \mathrm{m}$ pore size; Millipore, Billerica, MA, USA). After $24 \mathrm{~h}$ of co-culture beta cells were collected for flow cytometry or RNA isolation. Alexa647-anti-IgM (clone R33.24.12) was used for staining of bound $\operatorname{IgM}$ on beta cells. Negative controls consisted of beta cells with lymphocyte medium only in the transwells.

Statistical analysis Statistics were estimated by either Kruskal-Wallis or unpaired Student's $t$ test as specified in figure legends. Two-tailed tests with $95 \%$ confidence intervals were used and differences with $p<0.05$ were considered significant.

\section{Results}

High anti-insulin IgM level in the NOD mouse is independent of T cell autoreactivity To ascertain whether the NOD natural $\mathrm{AAb}$ repertoire was specifically directed to islet-related 
antigens, we quantified the serum concentration of total IgM and anti-insulin IgM in NOD and C57BL/6 mice from 3 to 12 weeks of age. Although no differences were found in total IgM levels (Fig. 1a), significantly increased levels of IgM with reactivity towards insulin were found in NOD mice (Fig. 1b). Importantly, these values were stable between 6 and 12 weeks indicating that they were not influenced by the progression of the disease in the NOD mouse. This suggests that the insulin IgM autoreactivity is a T-cell-independent, intrinsic characteristic of the NOD natural IgM repertoire. In support, we have analysed the profile of anti-insulin $\operatorname{IgM}$ secretion in C57BL/6.H2g7 mice, which have a genetic background similar to that of the $\mathrm{C} 57 \mathrm{BL} / 6$ parental strain but contain an MHC locus of NOD origin, and in the reciprocal NOD.H2b congenic strain that is protected from type 1 diabetes. The levels of anti-insulin IgM were significantly increased in the NOD.H2b compared with C57BL/6.H2g7 controls (Fig. 1c). No differences were found in total IgM concentration (data not shown).
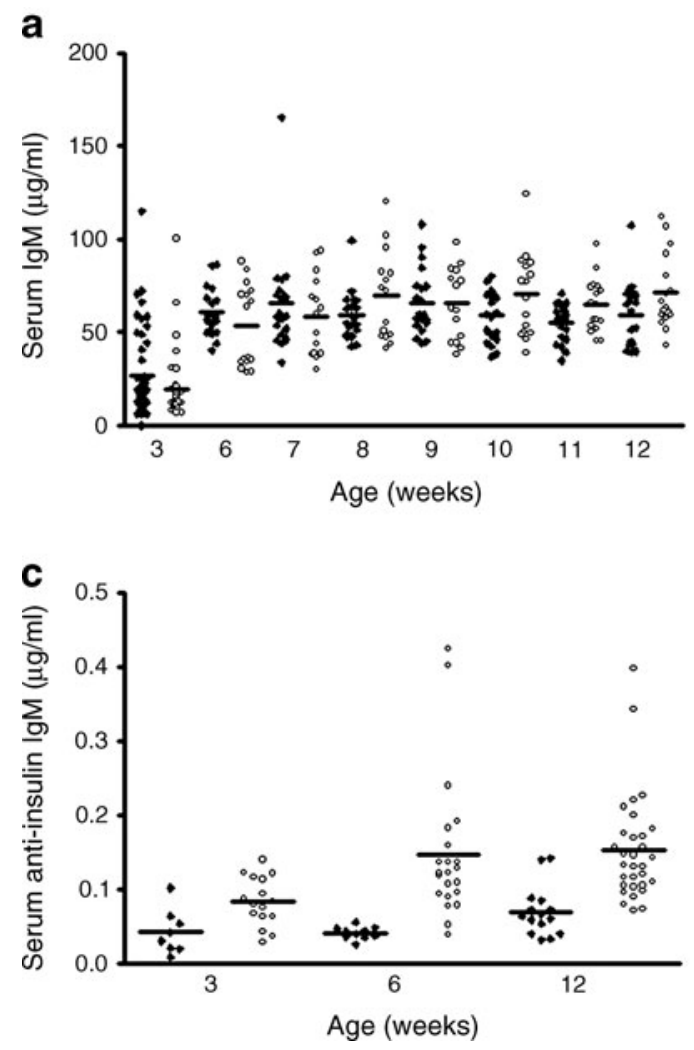

Fig. 1 Antibody IgM reactivity in the NOD mouse is biased towards type 1 diabetes antigens from pre-insulitic ages. Serum antibody concentration was measured individually by ELISA. Total IgM (a) and antiinsulin IgM (b) were assessed in groups of 13-47 C57BL/6 (black diamonds) or NOD (white circles) female mice at 3 weeks of age and over the interval of 6-12 weeks of age. Anti-insulin IgM was determined in groups of 8-31 C57BL/6.H2g7 (black diamonds) or NOD.H2b (white circles) female mice (c) and anti-insulin IgG was analysed in groups of
Additionally, we have analysed the global pattern of natural IgM reactivity by comparing the capacity of NOD and C57BL/6 serum IgM to recognise AAg present in NOD protein extracts and inferred that not only were there different patterns of IgM autoreactivity but also that global IgM reactivity was higher in NOD compared with C57BL/6 mice (ESM Fig. 2). We have also measured the serum levels of anti-insulin IgG in NOD and C57BL/6 mice. As expected, the reactivity profile was quite different from that observed for anti-insulin IgM. Although very low to undetectable levels were present in the serum of both strains up to 6 weeks, NOD mice had a progressive increase in antibody concentration that was most relevant at 12 weeks (Fig. 1d).

High proportion of NOD peritoneal cavity B1 a cells secretes anti-type 1 diabetes IgM in absence of patent insulitis In search of the cellular source for the altered natural antibody repertoire in the NOD mouse, we quantified the number of $\mathrm{B}$ cells secreting IgM that were able to recognise a pool of
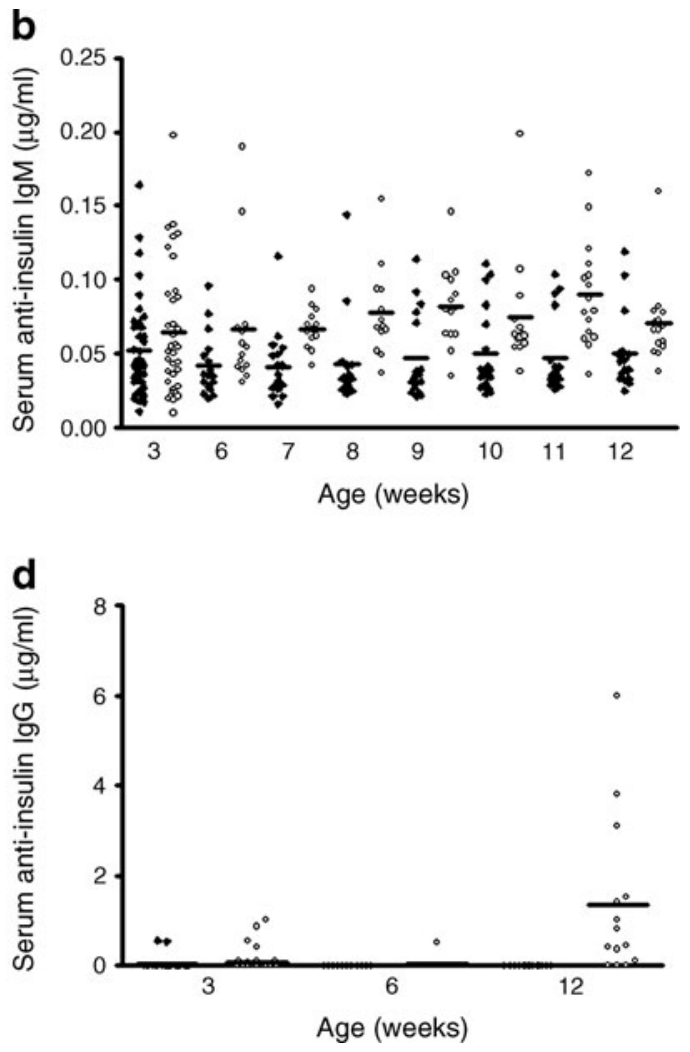

14-46 C57BL/6 (black diamonds) or NOD (white circles) female mice (d) at 3, 6 and 12 weeks of age. Average concentrations are shown as horizontal bars. Anti-insulin $\operatorname{IgM}(\mathbf{b}, \mathbf{c})$ and $\operatorname{IgG}(\mathbf{d})$ were different between strains over the interval 3-12 weeks of age $(p<0.0001)$ according to the Kruskal-Wallis test. NOD anti-insulin IgG concentration significantly increased with time $(p<0.0001)$ while NOD anti-insulin IgM did not vary in the age range of 6-12 weeks according to the Kruskal-Wallis test 
type 1 diabetes related AAg. We analysed the peritoneal B1a and $\mathrm{B} 1 \mathrm{~b}+\mathrm{B} 2$ cells and the splenic follicular $\mathrm{B}$ cells, marginal zone B cells and B1a cells (Fig. 2a). Already at 5 weeks of age the B1a cell peritoneal compartment contained the highest population of cells spontaneously secreting IgM with anti-
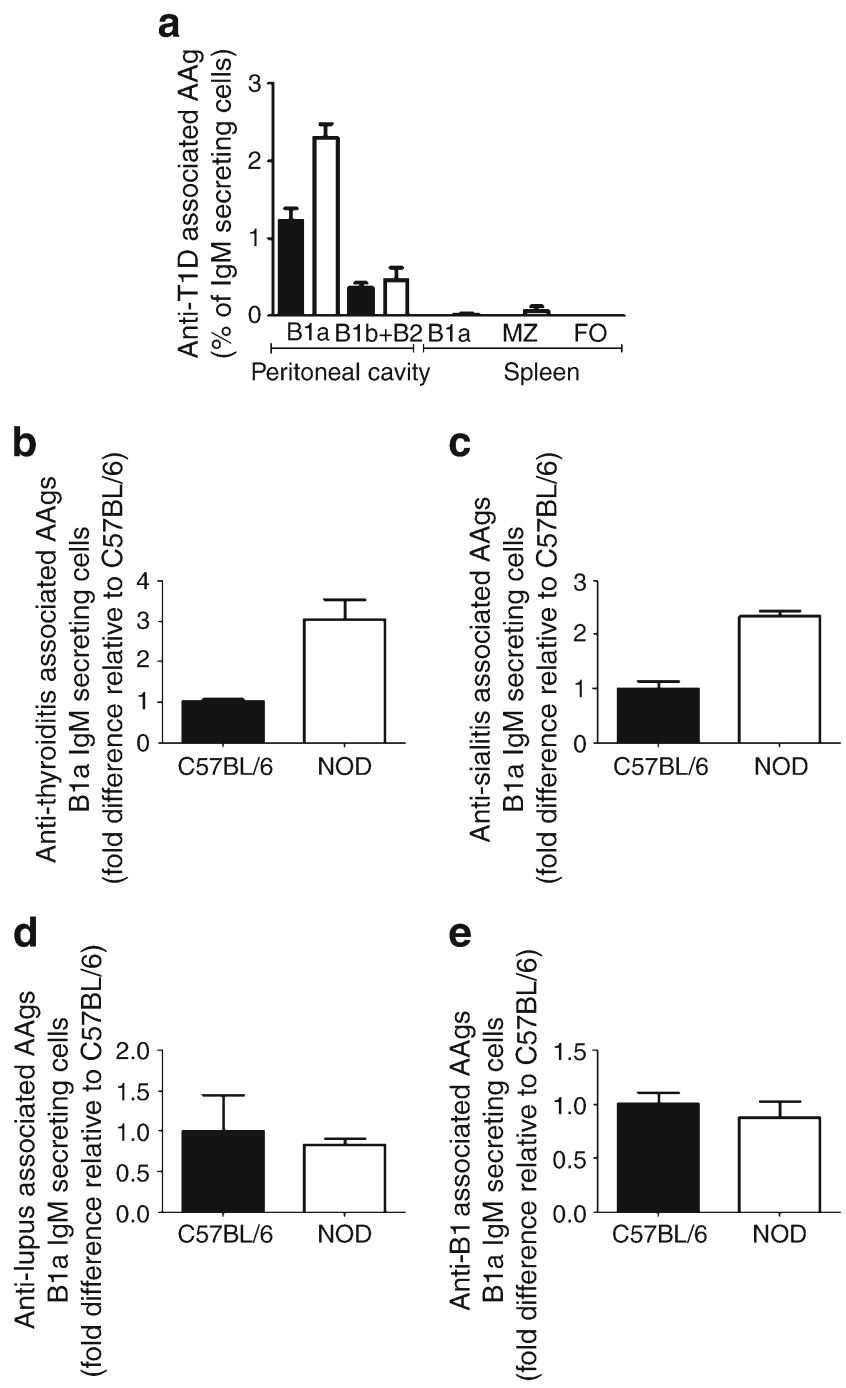

Fig. 2 Higher proportions of autoreactive IgM-secreting B1a cells are present in the NOD mouse peritoneal cavity. The percentages of cells spontaneously secreting IgM against the following antigens were determined by ELISPOT assays in C57BL/6 and NOD mice: a pool of insulin +GAD65+GAD67+IA-2 (type 1 diabetes AAgs) (a); thyroglobulin and thyroperoxidase (thyroiditis AAgs) (b); muscarinic-3receptor (sialitis AAg) (c); dsDNA, ssDNA and histone (lupus AAg) (d); and phosphatidylcholine, phosphorylcholine and dextran (B1 AAgs) (e). Peritoneal cavity B1a (a-e) and B1b+B2 cells, splenic follicular B cells, marginal zone B cells and splenic B1a cells (a) were purified from pooled samples of groups of 8-12 female mice between 3 and 5 weeks of age. The bars represent the average results of triplicates with the respective SD. Significant differences between strains were found in (a) $(p<0.01)$, in (b) $(p<0.05)$ and in (c) $(p<0.001)$ with the unpaired Student's $t$ test. Data are representative of three independent experiments. Black bars, C57BL/6 cells; white bars, NOD cells; FO, follicular; MZ, marginal zone; T1D, type 1 diabetes type 1 diabetes AAg reactivity. Importantly, there were significantly higher numbers of B1a cells secreting $\operatorname{IgM}$ with these reactivities in the NOD mice when compared with the C57BL/6 control mice, which is consistent with the pattern that we have found in the serum. We have detected a low proportion of antibody-secreting cells with anti-type 1 diabetes $\mathrm{AAg}$ reactivity in peritoneal $\mathrm{B} 1 \mathrm{~b}+\mathrm{B} 2$ cells, though no differences were observed between strains (Fig. 2a). In the splenic compartment the percentage of cells with these properties was either 0 or extremely low (Fig. 2a).

We next wanted to ascertain whether the observed difference in autoreactivity was restricted to type-1diabetes-associated AAg or whether it could represent a general feature of NOD B1a cells. Thus, we have quantified the proportion of $\mathrm{B} 1 \mathrm{a}$ cells secreting $\operatorname{IgM}$ recognising either a pool of AAg related to autoimmune thyroiditis (Fig. 2b), the main self-antigen of immune-mediated sialitis (Fig. 2c), a pool of antigens that are targets of SLE (Fig. 2d) or a pool of antigens that B1a cells generally recognise (Fig. 2e). Consistent with the NOD polyendocrine phenotype we detected more peritoneal B1a cells secreting IgM that recognised thyroiditis and sialitis AAgs (Fig. 2b,c), although no differences were found for the other AAgs tested (Fig. 2d,e).

NOD B1 a cells are B220 bright at 1 week of age Subsequently, we analysed whether the differences in $\mathrm{AAb}$ secretion patterns between the NOD and C57BL/6 mice could be attributed to disturbances in the peritoneal cavity B1a cell compartment. Although the proportion and numbers of peritoneal B cells did not differ between mouse strains, striking differences in the B1a surface phenotype could be observed (Fig. 3a,b) with NOD cells already expressing higher levels of B220 at 3 weeks (Fig. 3c,d). To understand the origin of this NOD distinctive feature, we have performed a time course analysis of $\mathrm{B} 1 \mathrm{a}$ cells both in the peritoneal cavity and in the spleen in comparison with C57BL/6. We found identical kinetics and no differences in B1a cells numbers in the peritoneal cavity (Fig. 4a). In the spleen, the B1a cell numbers were relatively similar, except at 1 and 12 weeks, at which times NOD mice had, respectively, slightly fewer or more B1a cells in comparison with $\mathrm{C} 57 \mathrm{BL} / 6$ mice (Fig. 4b). Interestingly, the NOD B1a cells both in peritoneal cavity and in the spleen consistently presented increased levels of B220 molecules on their surface, detected as early as at 1 week of age (Fig. 4c,d). In the peritoneal cavity, B220 intensity decreased with ageing, though the strain difference persisted (Fig. 4c). Intriguingly, the B220 levels were higher in NOD mouse spleen at around 2 weeks (Fig. 4d). 


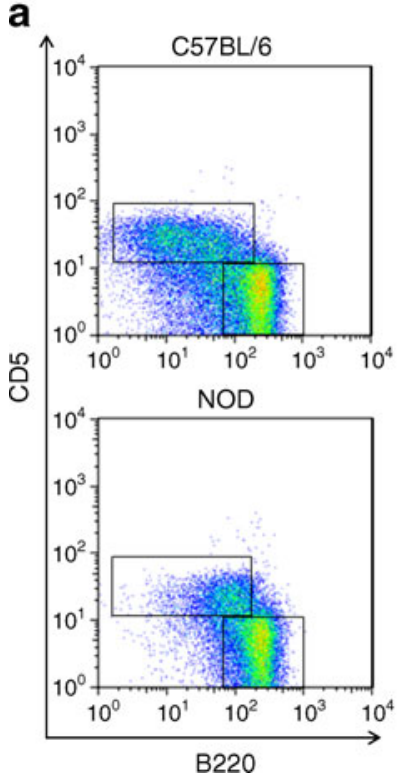

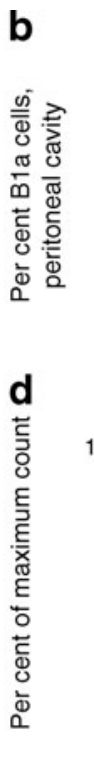
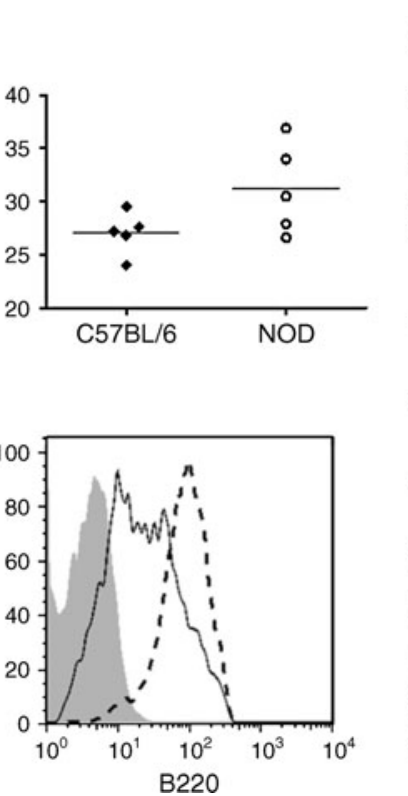
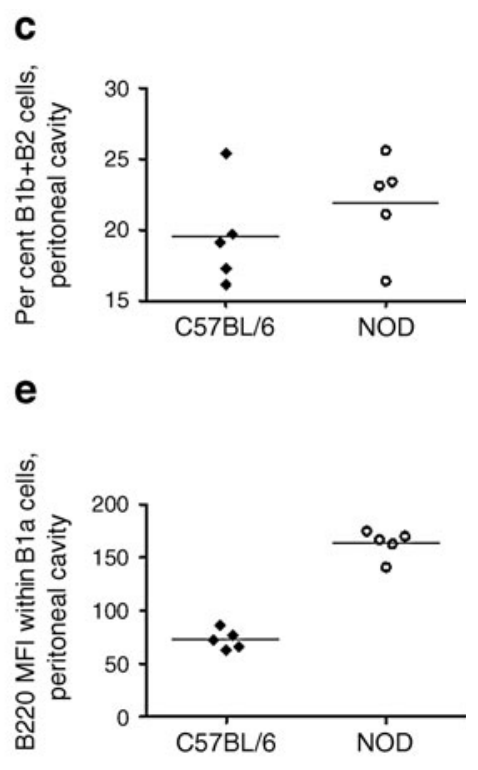

Fig. 3 NOD peritoneal cavity B1a cells are B220 high . Peritoneal cavity $\mathrm{B} 1 \mathrm{a}\left(\mathrm{B} 220^{+} \mathrm{CD}^{+}\right)$and $\mathrm{B} 1 \mathrm{~b}+\mathrm{B} 2\left(\mathrm{~B} 220^{+} \mathrm{CD} 5^{-}\right)$cell subpopulations were analysed by flow cytometry in NOD and C57BL/6. B220 and $\mathrm{CD} 5$ expression was evaluated within $\mathrm{CD} 19^{+} \mathrm{B}$ cells and representative dot plots are shown: (a) C57BL/6 cells and NOD cells. A representative histogram of typical B220 expression intensity within peritoneal cavity $\mathrm{CD} 19^{+} \mathrm{B}$ cells from $\mathrm{C} 57 \mathrm{BL} / 6$ (continuous black line) and NOD (dashed black line) cells is depicted together with an unstained control sample (grey shadow) (d). The individual percentages of $\mathrm{B} 1 \mathrm{a}$ and $\mathrm{B} 1 \mathrm{~b}+\mathrm{B} 2$ cells with respective mean values for five C57BL/6 or NOD female mice at 3 weeks of age are represented $(\mathbf{b}, \mathbf{c})$ as well as the B220 individual mean fluorescent intensity values from the same samples (e). Strain differences were found for B220 mean fluorescent intensity levels (d) $(p<0.0001)$ in the unpaired Student's $t$ test. Data are representative of more than three independent experiments. MFI, mean fluorescent intensity
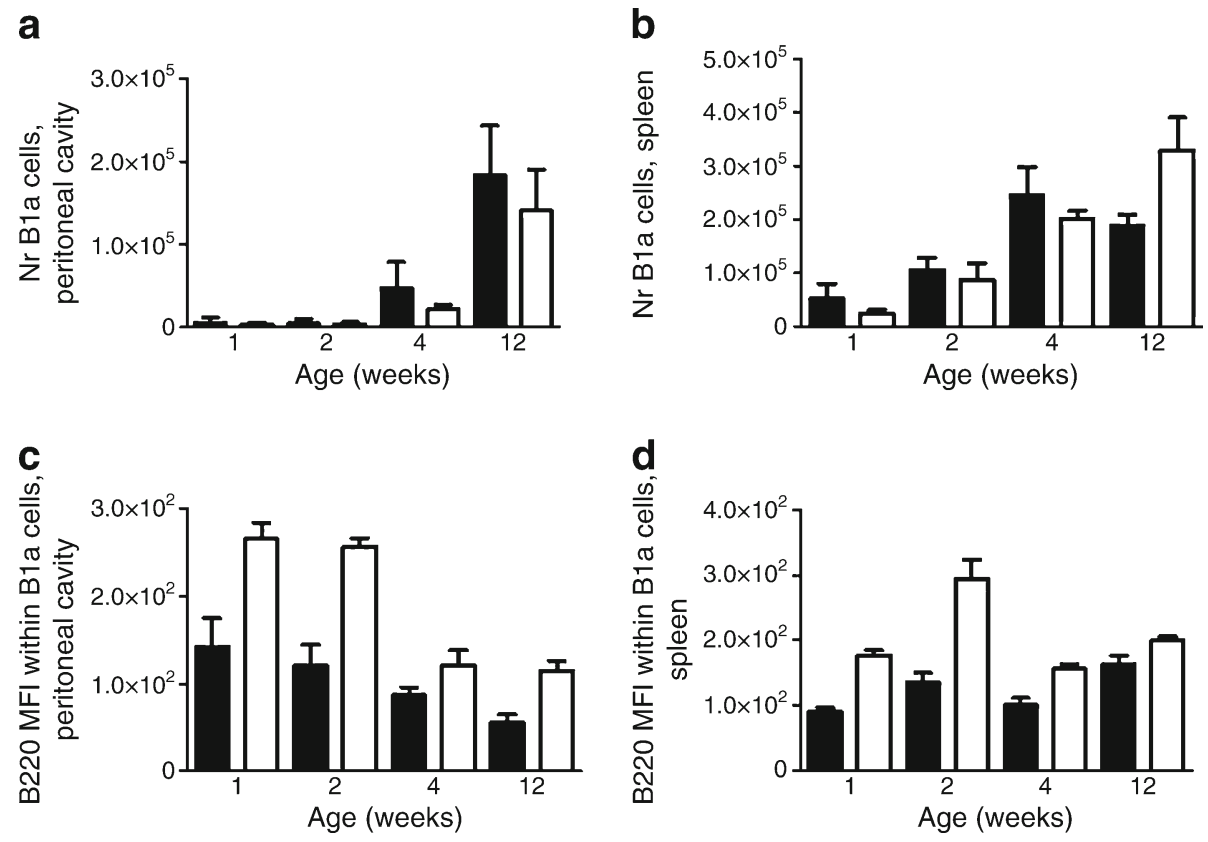

Fig. 4 Ontogenic distribution of B1a cells in the spleen and peritoneal cavity. The number of peritoneal cavity (a) and splenic (b) B1a cells and the B220 mean fluorescent intensity within the same populations (c and $\mathbf{d}$, respectively) were determined by flow cytometry at 1, 2, 4 and 12 weeks of age. The average results for four to nine C57BL/6 or NOD female mice are represented with the respective SD. Differences were found for B220 mean fluorescent intensity in NOD and C57BL/6

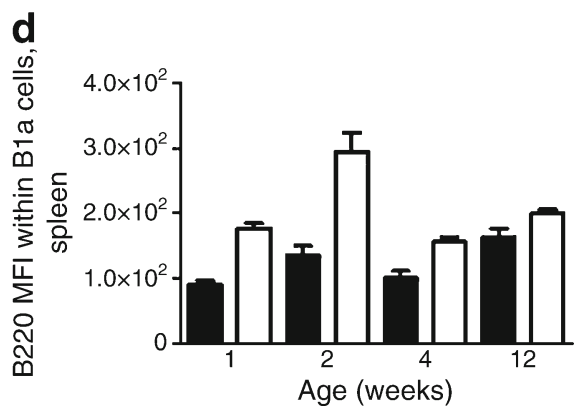

B1a cells for all analysed ages $(p<0.05)$ in unpaired Student's $t$ test. B1a numbers were identical between strains except at $1(p<0.05)$ and 12 weeks $(p<0.01)$ in the spleen in unpaired Student's $t$ test. Data are representative of two to four independent experiments for each time point. Black bars, C57BL/6 mice; white bars, NOD mice. MFI, mean fluorescent intensity 
Peritoneal cavity NOD B1 a cells display increased expression of surface activation molecules We hypothesised that the greatest expression of the B220 molecule on NOD B1a cells could be linked to increased basal activation. Indeed, already at 3 weeks NOD B1a cells showed decreased proportion of $\mathrm{CD} 43^{\text {high }}$ expression as compared with C57BL/6 (Fig. 5a). Also, NOD B1a cells expressed lower amounts of CD62L and showed enhanced expression of the co-stimulatory molecule CD86 (Fig. 5b,c). Thus, the surface phenotype of NOD B1a cells corroborates with the observed increased activation state at pre-insulitic stages. In addition, B1a cells expressed syndecan-1, indicating that some of these cells share the antibody secretion phenotype of plasma cells (Fig. 5d). Interestingly, the proportion of syndecan- $1^{+}$ B1a cells was consistently larger in the NOD mouse (Fig. 5e).

NOD B1 a cells secrete increased levels of autoantibodies on TLR stimulation The innate-like properties of B1a cell stimulation prompted us to test whether alterations in $T l r$ expression or response to TLR stimuli could condition the secretion profiles observed in the NOD B1a compartment. We quantified $T l r 2, T l r 4, T l r 6, T l r 7$ and $\operatorname{Tl} r 9$ mRNA levels in purified peritoneal NOD B1a cells in comparison with C57BL/6 mice and observed that all these genes were expressed at a higher level in the NOD mice (Fig. 6). To identify physiological correlates of these differences in gene expression we stimulated sorted B1a cells with purified LPS, a known ligand to TLR4, and found no consistent strain differences in CD69, CD86 or CD25 cell surface expression, indicating that similar activation levels were obtained (Fig. 7a-c). Despite seeing no differences in total IgM levels within the stimulated B1a cell supernatant fractions between NOD and C57BL/6 cells, the concentration of NOD IgM with reactivity to islet-related AAgs was consistently higher (Fig. 7d, e). Accordingly, an increased proportion of TLR4-stimulated NOD B1a cells secreted IgM with these specificities (ESM Fig. 3a), mimicking the secretion behaviour that we observed ex vivo. TLR4 stimulation induced potent secretion of the immunoregulatory cytokine IL10 by B1a cells, in contrast with the observed AAb secretion profile, and lower amounts were detected in the NOD B1a cell cultures (Fig. 7f). In addition, after 3 days of stimulation NOD B1a cell proliferation was substantially higher than in C57BL/6 (Fig. 7g). Similar observations were obtained on TLR9 stimulation (ESM Fig. 3b,c).

IgM secreted by NOD Bla cells can bind to pancreatic beta cells in vitro and trigger Nos 2 expression To analyse the mechanisms by which IgM of NOD B1a cell origin may contribute to disease, we have established in vitro cultures in
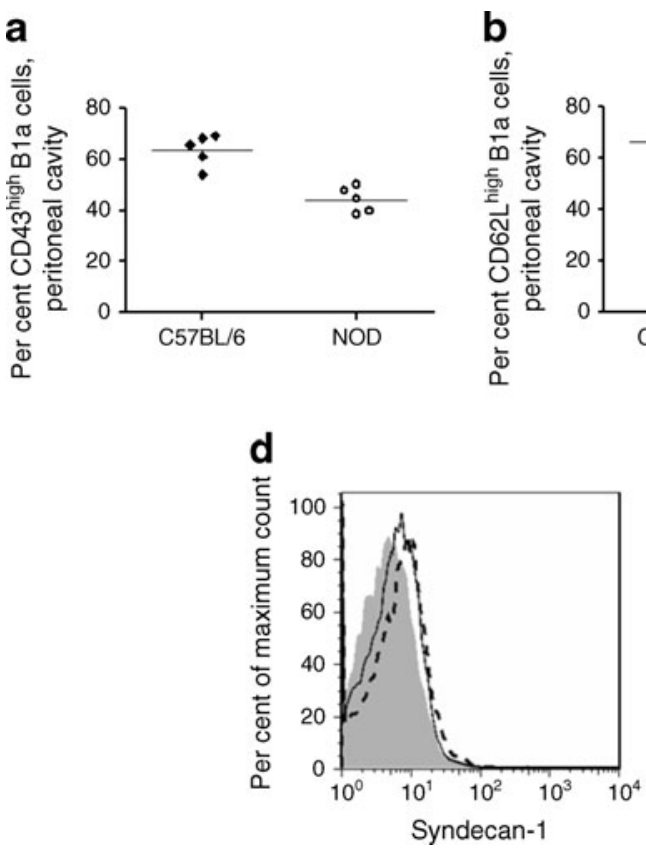

Fig. 5 Peritoneal cavity NOD B1a cells naturally display a surface phenotype of increased activation. Peritoneal cavity B1a cells were analysed in five C57BL/6 or NOD female mice at 3 weeks of age. The expression of CD43 (a), CD62L (b), CD86 (c) and syndecan-1 (d, e) was assessed by flow cytometry. Individual percentages and the respective means are represented $(\mathbf{a}-\mathbf{c}, \mathbf{e})$. A typical syndecan-1
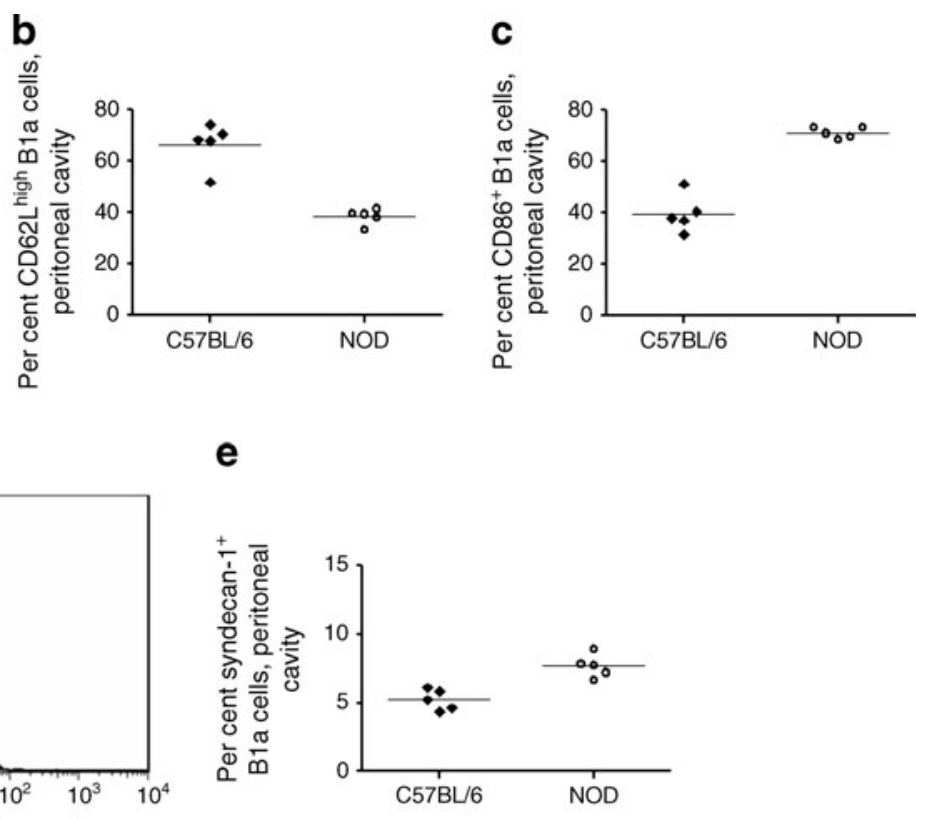

expression histogram (d) is shown for C57BL/6 (continuous black line) and NOD (dashed black line) mice together with an unstained control sample (grey shadow). Differences were found in the expression of all the referred cell surface activation markers $(p<0.01)$ in the unpaired Student's $t$ test. Data are representative of three independent experiments 

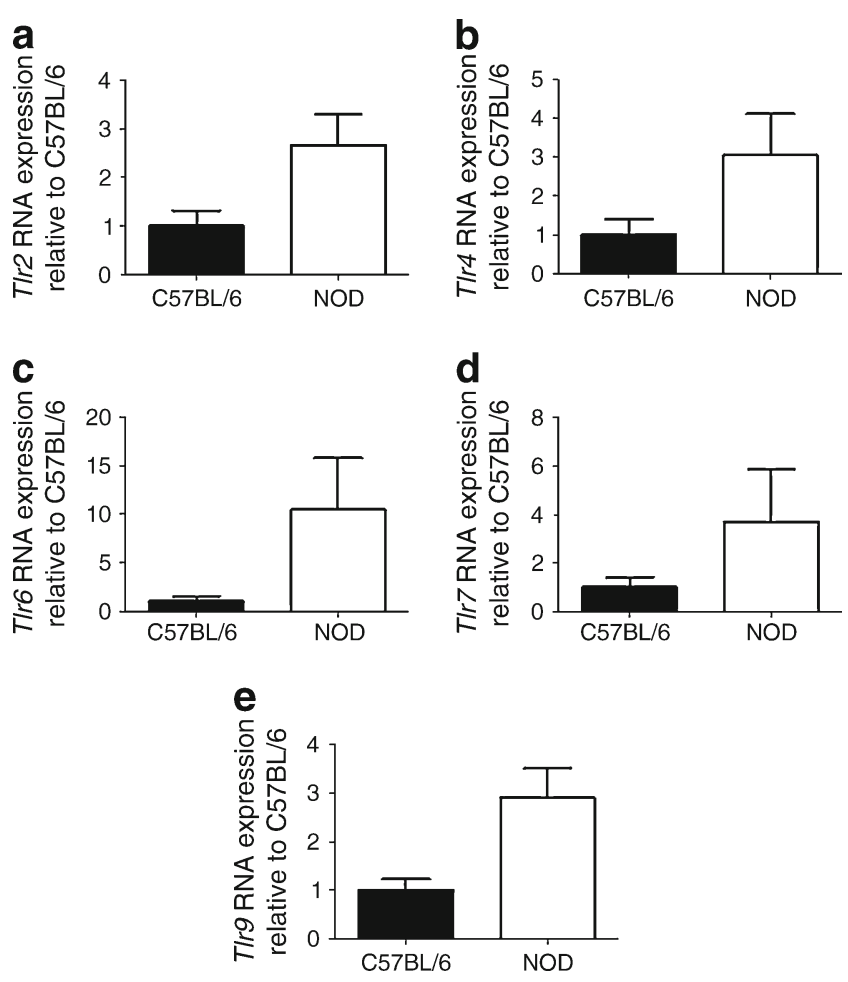

Fig. $6 \mathrm{Tl}$ gene expression is increased in peritoneal cavity B1a cells from young NOD mice. Purified peritoneal B1a cells were obtained from 15 female mice of 3 weeks of age and pooled for RNA extraction. TaqMan gene expression assays were then used to quantify the expression of $\operatorname{Tl} 2$ (a), $\operatorname{Tl} 4$ (b), $\operatorname{Tlr} 6(\mathbf{c}), \operatorname{Tl} 7$ (d) and $\operatorname{Tl} 9$ (e) as indicated. Relative quantification of these genes was obtained in triplicate, after normalisation to Gapdh expression. Mean fold differences from C57BL/6 cells and the respective SD from a pool of two identical experiments are represented. Differences were found for all the studied genes $(p<0.05)$ in unpaired Student's $t$ tests

which secreted antibody but not B cells are in contact with beta cells. We have purified NOD peritoneal B1a cells and splenic follicular B cells and cultured them in transwells with dispersed pancreatic islets of Langerhans from immunodeficient NOD.SCID mice (Fig. 8a). After $24 \mathrm{~h}$ of culture, beta cells were analysed for the presence of bound $\operatorname{IgM}$ (Fig. 8b). Beta cells could be distinguished by their size, granulosity and autofluorescence in the FL1-H channel (Fig. 8a, b). In agreement with our analysis of IgM reactivity, beta cells that were co-cultured with sorted B1a cells presented IgM bound on their surface. However, beta cells cocultured with follicular B cells showed only background levels of IgM staining (Fig. 8b, c). Using the same system we next analysed the expression levels of genes associated with pancreatic beta cell responses to stress. This analysis revealed upregulation of the gene encoding the inducible form of nitric oxide synthase (Nos2) in islet cells co-cultured with NOD B1a cells when compared with beta cells cultured with medium alone (Fig. 9). No difference was observed in the expression of Fas, Casp3 and Ccl2 (Fig. 9) nor in cell viability measured by Hoescht/propidium iodine staining after $24 \mathrm{~h}$ of culture (data not shown).

\section{Discussion}

This study demonstrates that NOD B1a cells have an increased responsiveness to innate activation and secrete NAbs with higher reactivity to type-1-diabetes-associated AAg. Importantly, NOD-B1a-cell-derived IgM is able to bind pancreatic beta cells and trigger Nos 2 expression, a starting point in the beta cell oxidative stress response. Together, these results provide evidence to support the proposal that the NOD natural AAb repertoire is biased from an early age towards endocrine autoreactivity, thus having the potential to fuel the autoimmune beta cell attack prior to the T-cell-mediated destruction.

In our time-course analysis NOD mice presented increased but stable serum levels of IgM with insulin reactivity when compared with C57BL/6 mice. This pattern of natural antibody autoreactivity did not correlate with the IgG serum levels that clearly followed the progression of the disease in the NOD mouse (Fig. 1d and Koczwara et al [31]). The remarkably different trajectories of serum antiinsulin IgG or IgM isotypes highlight their different roles in the NOD immune response. While the detection of antitype-1-diabetes-AAg IgG is widely accepted as an early disease marker in clinical practice and is generally considered to be a by-product of the T-cell-mediated destruction of beta cells $[32,33]$, autoreactive IgM comprises the pool of NAbs, the first antibodies to arise during ontogeny, produced in the absence of exogenous stimuli [34]. Analysis of MHC congenic strains [35] showed that, unlike IgG, IgM reactivity observed in the NOD cells is independent of T cell help and disease progression, and is consistent with the hypothesis that an increased autoreactivity in the NOD $\mathrm{NAb}$ compartment would contribute to the initiation of autoimmunity [26]. This suggested the possibility that IgM reactivities would also be altered in human type 1 diabetes and we have preliminary evidence that common genetic variants (single-nucleotide polymorphisms) in the IgM locus control the levels of anti-GAD serum IgM and are associated with disease in a collection of type 1 diabetes patients (I. Rolim, G. Barata, J. Raposo, M. Catarino, C. Penha-Gonçalves, unpublished results). These findings strengthen the link between NAbs and type 1 diabetes pathogenesis and give importance to further investigations into the origin of autoreactive IgM.

We found that B220 expression strikingly distinguished NOD B1a cells in the peritoneal cavity from as early as 1 week of age, as compared with $\mathrm{C} 57 \mathrm{BL} / 6$ and $\mathrm{BALB} / \mathrm{c}$ cells (not shown). Interestingly, peritoneal B1a cells that 


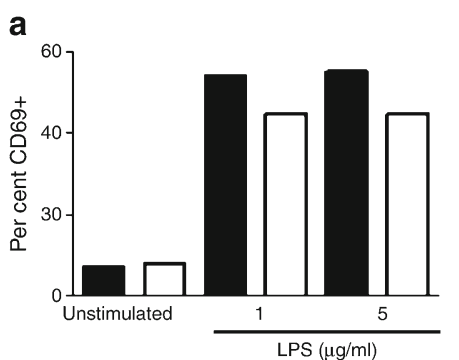

d

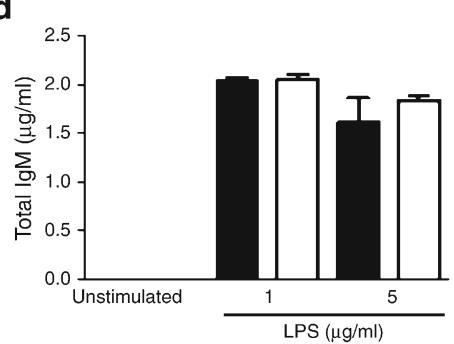

f

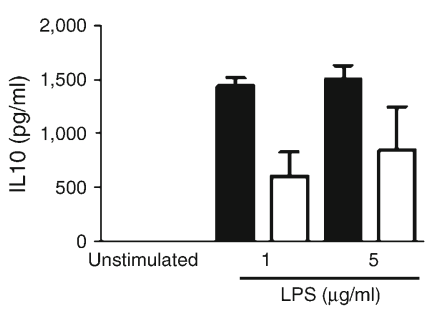

b

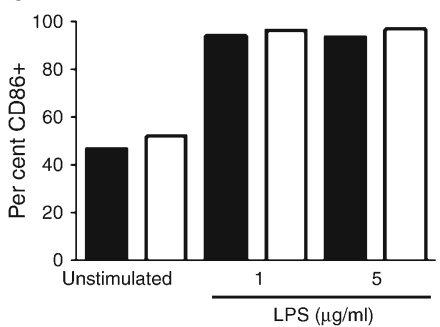

C

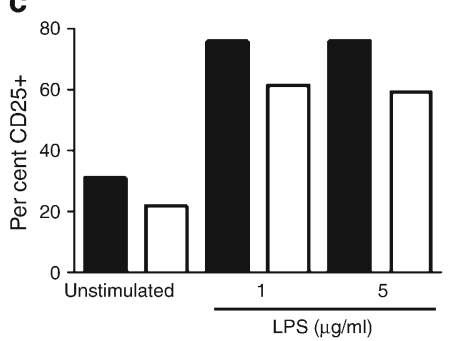

e

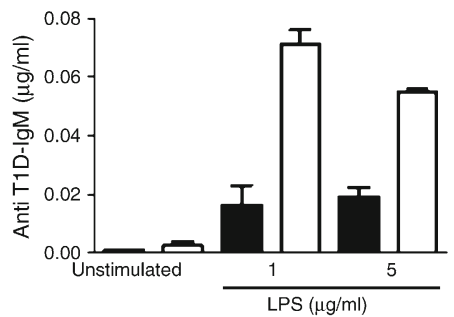

g

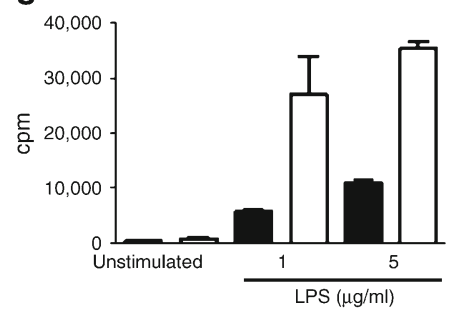

of duplicate samples is represented with the respective SD, except for activation markers analysis, for which pooled duplicates were used for flow cytometry acquisition. Strain differences were found for antitype-1-diabetes-AAg IgM concentration in supernatant fractions of B1a cells stimulated with both 1 and $5 \mu \mathrm{g} / \mathrm{ml}$ of LPS $(p<0.05)$, for IL10 levels in supernatant fractions of B1a cells stimulated with $1 \mu \mathrm{g} / \mathrm{ml}$ of LPS $(p<0.05)$ and for proliferation after 3 days of $5 \mu \mathrm{g} / \mathrm{ml} \mathrm{LPS}$ stimulation $(p<0.01)$ in unpaired Student's $t$ tests. Data are representative of two independent experiments. Black bars, C57BL/6 mice; white bars, NOD mice; T1D, type 1 diabetes

B1 cell traits $[19,20]$. Thus, peritoneal cavity B1a cells are able to respond rapidly to external stimuli, namely microbial alterations in the intestine, leaving open the possibility that IgA-secreting B1a cells residing in the gut could influence the effect of microflora components on the development of diabetes in the NOD mouse [42]. Our observations of higher B220 and $\mathrm{Tlr}$ expression at an early age and increased proliferation upon TLR4 stimulation concur to suggest strongly that B1a B220 high cells may represent a B1 cell population in the NOD mouse that colonises the peritoneal cavity in early ontogeny and is exquisitely sensitive to innate stimuli.

In accordance, NOD B1a TLR stimulation resulted in increased levels of IgM secretion with reactivity against type 1 diabetes AAg while the secretion of IL10 remained lower when compared with C57BL/6 B1a cells. Stimulation through 
a

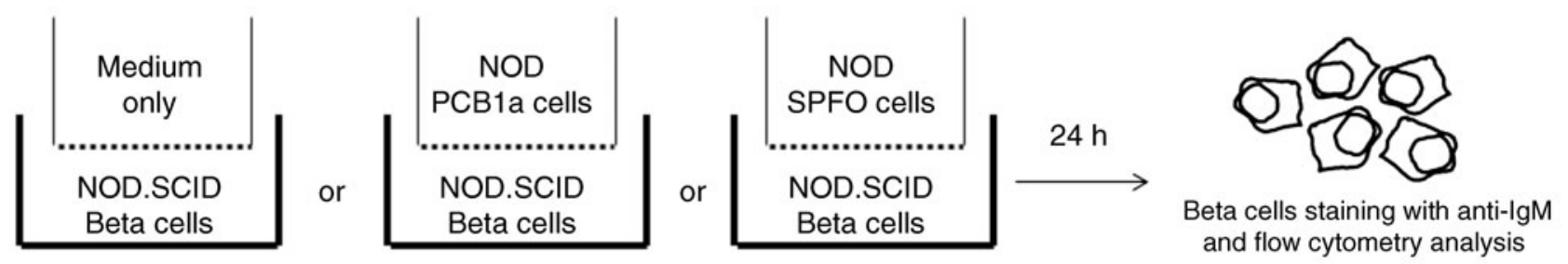

b

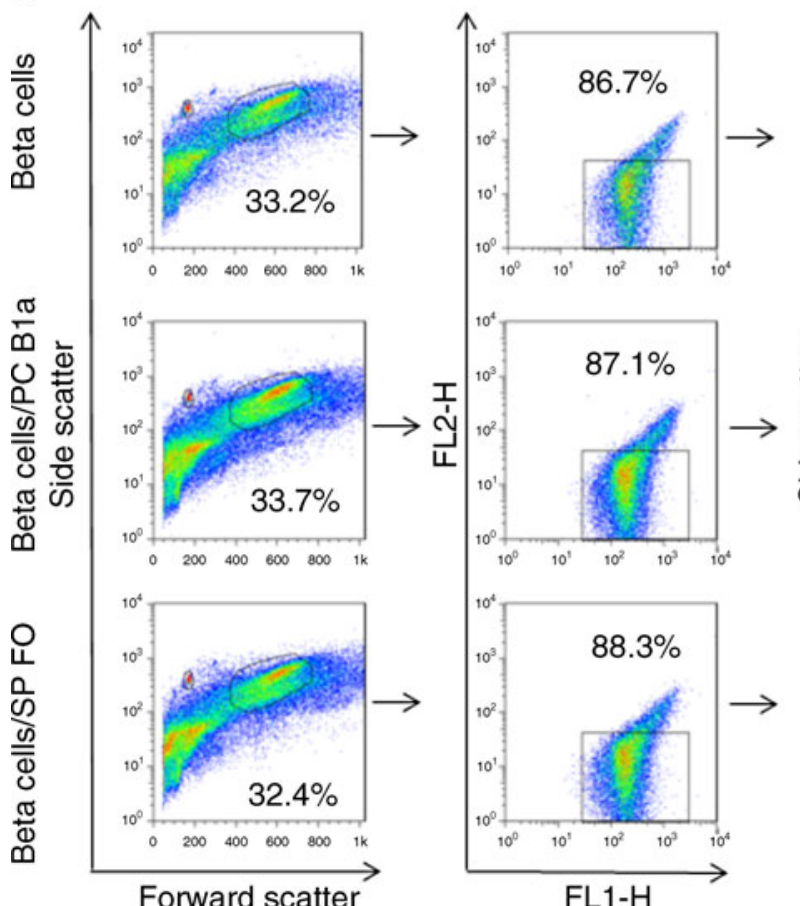

Forward scatter

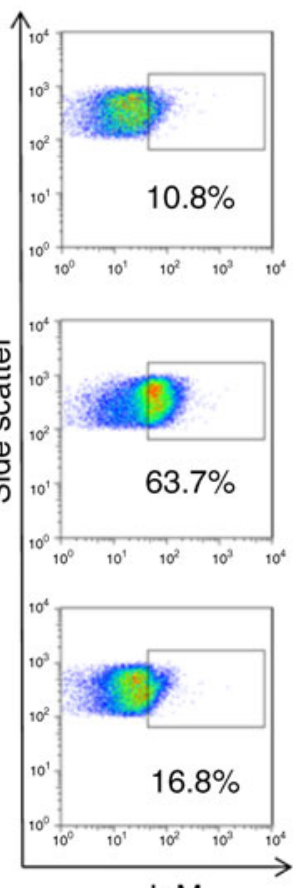

$\lg \mathrm{M}$

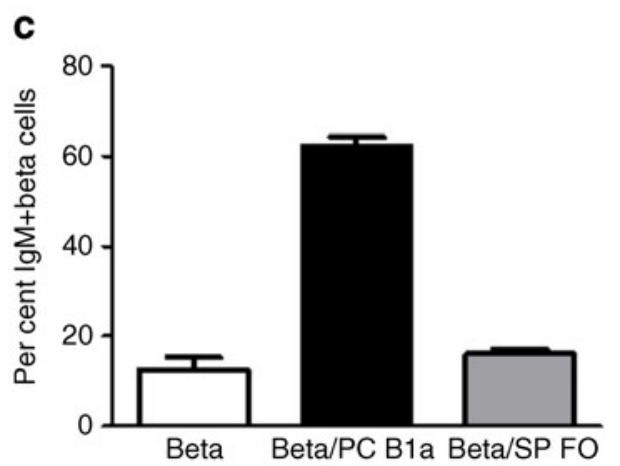

Fig. 8 IgM secreted by NOD B1a cells binds to NOD.SCID pancreatic beta cells in vitro. The enriched beta cell population collected from nine NOD.SCID female mice at 9 weeks of age was co-cultured in a transwell system with purified peritoneal cavity B1a cells or splenic follicular B cells obtained from 15 NOD female mice at 7-10 weeks of age. After $24 \mathrm{~h}$, beta cells were stained and the presence of bound IgM was analysed by flow cytometry (a). Beta cells cultured in transwells with lymphocyte culture medium only were used as negative controls. Representative dot plots of the beta cells morphological gate, auto- fluorescence in FL1-H channel and IgM staining are represented for each experimental condition (b). The mean and SD of duplicates are shown in (c). Beta cells co-cultured with sorted B1a cells presented increased levels of IgM bound on their surface (c), in comparison with negative controls (beta cells) and beta cells co-cultured with follicular $\mathrm{B}$ cells from the spleen $(p<0.01)$ in unpaired Student's $t$ tests. Data are representative of three independent experiments. PC B1a, peritoneal cavity B1a cells; SP FO, splenic follicular B cells
TLRs has been shown to strongly promote plasma cell differentiation in the B1 cell compartment [21]. Interestingly, NOD B1a cells produced amounts of total IgM similar to those produced by $\mathrm{C} 57 \mathrm{BL} / 6$ cells in the presence of TLR ligands. This indicates that the NOD B1a cell population harbours an increased population of autoreactive cells with increased responsiveness and propensity for plasma cell differentiation on innate stimulation. This is in agreement with increased numbers of NOD B1a cells secreting IgM with reactivity towards endocrine AAgs and with the pattern of serum anti-insulin IgM.

Importantly, we did not detect strain differences in the numbers of B1a cells in the pancreatic lymph nodes, nor their presence in the pancreas of prediabetic NOD mice (data not shown), strengthening the hypothesis that the role of NOD B1a cells on type 1 diabetes onset may be mediated by autoreactive IgM [26]. Accordingly, binding of IgM to beta cells has been described in vivo in very young NOD mice [10]. We showed here that NOD B1a-derived IgM binds to beta cells in vitro and that the expression of Nos2 is upregulated in islet cells in contact with NOD B1a-derived supernatant fraction, suggesting that IgM binding is involved in triggering the beta cell oxidative stress response. However, Fas, Casp 3 and $C c l 2$ gene expression was not altered, indicating that the pattern of gene induction differed 
a

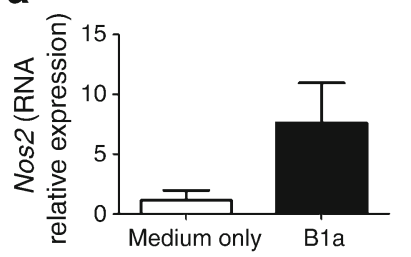

C

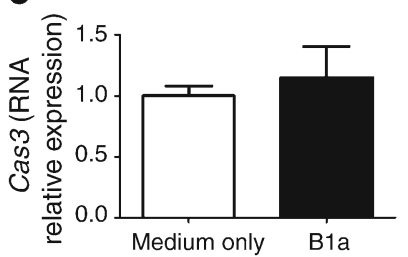

b

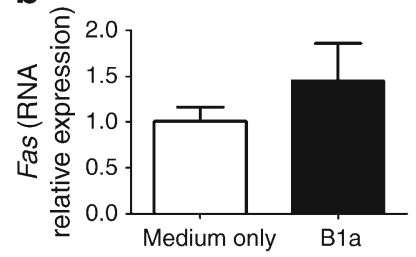

d

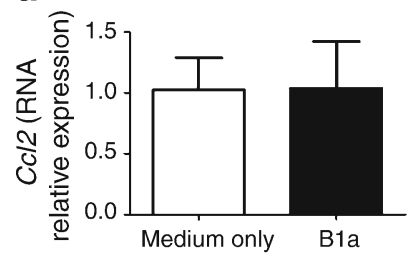

Fig. 9 In vitro autoreactive natural $\operatorname{IgM}$ binding in pancreatic beta cells triggers Nos 2 expression. Dispersed pancreatic islets of Langerhans obtained from nine NOD.SCID female mice at 9 weeks of age were co-cultured in duplicates in a transwell system with purified peritoneal cavity B1a cells collected from 12-14 NOD female mice at 9-10 weeks of age. After $24 \mathrm{~h}$, beta cells RNA was extracted and TaqMan gene expression assays were used to quantify the expression of $N o s 2$ (a), Fas (b), Casp3 (c), and Ccl2 (d). Relative quantification of these genes was obtained in triplicates of each sample, after normalisation to Gapdh expression. Average fold differences with SD from a pool of two identical experiments are represented in relation to negative controls (beta cells were co-cultured with lymphocyte medium only). Differences were detected for Nos 2 expression $(p<0.05)$ in unpaired Student's $t$ tests

from that described for cytokine-induced beta cell damage [43]. This reinforces the notion that the effects observed in Nos 2 expression are due to the binding of autoreactive IgM, a hypothesis that requires further confirmation. In addition, the binding of IgM did not induce the expression of apoptosis-related genes, nor a decrease in beta cell viability as determined by vital staining at $24 \mathrm{~h}$ of culture (data not shown). Nevertheless, specific assays for apoptosis or longer co-culture periods would be necessary to demonstrate if IgM binding impacts on beta cell viability. Whether other immunological components, such as complement in the serum, could potentiate the IgM effect and determine the fate of beta cells in type 1 diabetes remains to be addressed.

In conclusion, in this study we have linked alterations in the B1a cell population to serum IgM autoreactivities and beta cell oxidative stress, strengthening the hypothesis that NAbs are an early factor in the evolution of diabetes pathogenesis in the NOD mouse model of type 1 diabetes.

Acknowledgements We wish to thank D. Eizirik (Laboratoire de Médecine Expérimentale, Faculté de Médecine, Université Libre de Bruxelles, Brussels, Belgium) for providing training on beta cell isolation and J. W. Thomas (Vanderbilt University Medical Center, Nashville, TN, USA) for kindly providing the anti-insulin IgM

antibody. We are grateful to C. Fesel (Instituto Gulbenkian de Ciência, Oeiras, Portugal) for help with the 'Panama' blot technique and R. M. Parkhouse (Instituto Gulbenkian de Ciência, Oeiras, Portugal) for useful suggestions and discussions and to both of them for critically reading the manuscript.

Funding We acknowledge Fundacão para a Ciência e a Tecnologia for financial support of J. Côrte-Real with grant SFRH/BD/29212/ 2006, and N. Duarte with grant SFRH/BPD/43631/2008.

Contribution statement CP-G and LT contributed to the conception and design of this study and critical reviewed the intellectual content of this manuscript. ND and JC-R contributed equally to the collection, analysis and interpretation of data as well as to the conception, design and drafting of this article. All authors approved the final version of the article to be published.

Duality of interest The authors declare that there is no duality of interest associated with this manuscript.

\section{References}

1. Patterson CC, Dahlquist GG, Gyurus E, Green A, Soltesz G (2009) Incidence trends for childhood type 1 diabetes in Europe during 1989-2003 and predicted new cases 2005-20: a multicentre prospective registration study. Lancet 373:2027-2033

2. Castano L, Eisenbarth GS (1990) Type-I diabetes: a chronic autoimmune disease of human, mouse, and rat. Annu Rev Immunol 8:647-679

3. Bach JF (1994) Insulin-dependent diabetes mellitus as an autoimmune disease. Endocr Rev 15:516-542

4. Serreze DV, Chapman HD, Varnum DS et al (1996) B lymphocytes are essential for the initiation of $\mathrm{T}$ cell-mediated autoimmune diabetes: analysis of a new "speed congenic" stock of NOD.Ig mu null mice. J Exp Med 184:2049-2053

5. Leslie D, Lipsky P, Notkins AL (2001) Autoantibodies as predictors of disease. J Clin Invest 108:1417-1422

6. Noorchashm H, Lieu YK, Noorchashm N et al (1999) I-Ag7mediated antigen presentation by B lymphocytes is critical in overcoming a checkpoint in $\mathrm{T}$ cell tolerance to islet beta cells of nonobese diabetic mice. J Immunol 163:743-750

7. Hulbert C, Riseili B, Rojas M, Thomas JW (2001) B cell specificity contributes to the outcome of diabetes in nonobese diabetic mice. J Immunol 167:5535-5538

8. Wong FS, Wen L, Tang M et al (2004) Investigation of the role of B-cells in type 1 diabetes in the NOD mouse. Diabetes 53:25812587

9. Yang Y, Santamaria P (2003) Dissecting autoimmune diabetes through genetic manipulation of non-obese diabetic mice. Diabetologia 46:1447-1464

10. Shieh DC, Cornelius JG, Winter WE, Peck AB (1993) Insulindependent diabetes in the NOD mouse model. I. Detection and characterization of autoantibody bound to the surface of pancreatic beta cells prior to development of the insulitis lesion in prediabetic NOD mice. Autoimmunity 15:123-135

11. Thomas JW, Kendall PL, Mitchell HG (2002) The natural autoantibody repertoire of nonobese diabetic mice is highly active. J Immunol 169:6617-6624

12. Casali P, Schettino EW (1996) Structure and function of natural antibodies. Curr Top Microbiol Immunol 210:167-179 
13. Herzenberg LA (2000) B-1 cells: the lineage question revisited. Immunol Rev 175:9-22

14. Stall AM, Wells SM, Lam KP (1996) B-1 cells: unique origins and functions. Semin Immunol 8:45-59

15. Ochsenbein AF, Fehr T, Lutz C et al (1999) Control of early viral and bacterial distribution and disease by natural antibodies. Science 286:2156-2159

16. Martin F, Oliver AM, Kearney JF (2001) Marginal zone and B1 $\mathrm{B}$ cells unite in the early response against $\mathrm{T}$-independent bloodborne particulate antigens. Immunity 14:617-629

17. Bikah G, Carey J, Ciallella JR, Tarakhovsky A, Bondada S (1996) CD5-mediated negative regulation of antigen receptor-induced growth signals in B-1 B cells. Science 274:1906-1909

18. Gary-Gouy H, Harriague J, Bismuth G, Platzer C, Schmitt C, Dalloul AH (2002) Human CD5 promotes B-cell survival through stimulation of autocrine IL-10 production. Blood 100:4537-4543

19. Alam C, Valkonen S, Palagani V, Jalava J, Eerola E, Hanninen A (2010) Inflammatory tendencies and overproduction of IL-17 in the colon of young NOD mice are counteracted with diet change. Diabetes 59:2237-2246

20. Alam C, Bittoun E, Bhagwat D et al (2011) Effects of a germ-free environment on gut immune regulation and diabetes progression in non-obese diabetic (NOD) mice. Diabetologia 54:1398-1406

21. Genestier L, Taillardet M, Mondiere P, Gheit H, Bella C, Defrance T (2007) TLR agonists selectively promote terminal plasma cell differentiation of B cell subsets specialized in thymus-independent responses. J Immunol 178:7779-7786

22. Ryan GA, Wang CJ, Chamberlain JL et al (2010) B1 cells promote pancreas infiltration by autoreactive $\mathrm{T}$ cells. J Immunol 185:2800-2807

23. Rojas M, Hulbert C, Thomas JW (2001) Anergy and not clonal ignorance determines the fate of $\mathrm{B}$ cells that recognize a physiological autoantigen. J Immunol 166:3194-3200

24. Gyarmati J, Szekeres-Bartho J, Fischer B, Soltesz G (1999) Fetal type lymphocytes in insulin dependent diabetes mellitus. Autoimmunity 30:63-69

25. Kendall PL, Woodward EJ, Hulbert C, Thomas JW (2004) Peritoneal B cells govern the outcome of diabetes in non-obese diabetic mice. Eur J Immunol 34:2387-2395

26. Corte-Real J, Duarte N, Tavares L, Penha-Goncalves C (2009) Autoimmunity triggers in the NOD mouse: a role for natural auto-antibody reactivities in type 1 diabetes. Ann N Y Acad Sci 1173:442-448

27. U.S. Department of Health and Human Service, Office of Extramural Research, National Institutes of Health, Office of Laboratory Animal Welfare (1985) Public Health Service Policy on Humane Care and Use of Laboratory Animals "Animals in Research". Available from http://grants1.nih.gov/grants/olaw/references/ phspol.htm, accessed 6 August 2011

28. Baumgarth N, Tung JW, Herzenberg LA (2005) Inherent specificities in natural antibodies: a key to immune defense against pathogen invasion. Springer Semin Immunopathol 26:347-362
29. Corte-Real J, Rodo J, Almeida P et al (2009) Irf4 is a positional and functional candidate gene for the control of serum IgM levels in the mouse. Genes Immun 10:93-99

30. Livak KJ, Schmittgen TD (2001) Analysis of relative gene expression data using real-time quantitative PCR and the 2(-Delta Delta C(T)) Method. Methods 25:402-408

31. Koczwara K, Schenker M, Schmid S, Kredel K, Ziegler AG, Bonifacio E (2003) Characterization of antibody responses to endogenous and exogenous antigen in the nonobese diabetic mouse. Clin Immunol 106:155-162

32. Yu L, Robles DT, Abiru N et al (2000) Early expression of antiinsulin autoantibodies of humans and the NOD mouse: evidence for early determination of subsequent diabetes. Proc Natl Acad Sci U S A 97:1701-1706

33. Serreze DV, Fleming SA, Chapman HD, Richard SD, Leiter EH, Tisch RM (1998) B lymphocytes are critical antigen-presenting cells for the initiation of $\mathrm{T}$ cell-mediated autoimmune diabetes in nonobese diabetic mice. J Immunol 161:3912-3918

34. Meffre E, Salmon JE (2007) Autoantibody selection and production in early human life. J Clin Invest 117:598-601

35. Wicker LS, Appel MC, Dotta F et al (1992) Autoimmune syndromes in major histocompatibility complex (MHC) congenic strains of nonobese diabetic (NOD) mice. The NOD MHC is dominant for insulitis and cyclophosphamide-induced diabetes. J Exp Med 176:67-77

36. Wardemann H, Boehm T, Dear N, Carsetti R (2002) B-1a B cells that link the innate and adaptive immune responses are lacking in the absence of the spleen. J Exp Med 195:771-780

37. Esplin BL, Welner RS, Zhang Q, Borghesi LA, Kincade PW (2009) A differentiation pathway for B1 cells in adult bone marrow. Proc Natl Acad Sci U S A 106:5773-5778

38. Casola S, Otipoby KL, Alimzhanov M et al (2004) B cell receptor signal strength determines B cell fate. Nat Immunol 5:317-327

39. Jellusova J, Wellmann U, Amann K, Winkler TH, Nitschke L (2010) CD22 x Siglec-G double-deficient mice have massively increased B1 cell numbers and develop systemic autoimmunity. J Immunol 184:3618-3627

40. Lampeter EF, Signore A, Gale EA, Pozzilli P (1989) Lessons from the NOD mouse for the pathogenesis and immunotherapy of human type 1 (insulin-dependent) diabetes mellitus. Diabetologia 32:703-708

41. Alam C, Valkonen S, Ohls S, Tornqvist K, Hanninen A (2010) Enhanced trafficking to the pancreatic lymph nodes and autoantigen presentation capacity distinguishes peritoneal B lymphocytes in non-obese diabetic mice. Diabetologia 53:346-355

42. King C, Sarvetnick N (2011) The incidence of type-1 diabetes in NOD mice is modulated by restricted flora not germ-free conditions. PLoS One 6:e17049

43. Cardozo AK, Kruhoffer M, Leeman R, Orntoft T, Eizirik DL (2001) Identification of novel cytokine-induced genes in pancreatic beta-cells by high-density oligonucleotide arrays. Diabetes 50:909-920 